\title{
Uncomplicated urinary tract infections in the emergency department: a review of local practice patterns
}

\author{
Elizabeth Poon, MD*; Lauren Self, MD*; Shelley L. McLeod, MSc, PhD $(c)^{*{ }^{\dagger *}}$; Sean Caine, $\mathrm{MD}^{* \dagger \xi}$; \\ Bjug Borgundvaag, MD, $\mathrm{PhD}^{*^{\dagger \ddagger}}$
}

\section{ABSTRACT}

Objectives: To determine the number of urine cultures ordered for women who presented to the emergency department (ED) with symptoms of uncomplicated UTI, and whether a culture result impacted subsequent management. Methods: This was a retrospective chart review of nonpregnant women aged 18-39 presenting to one of two academic EDs with a discharge diagnosis of uncomplicated UTI over a one-year study period. Patients were excluded if there was documentation of fever, immunocompromised state, diabetes mellitus, absence of lower urinary tract symptoms, ED administration of intravenous antibiotics, a previous UTI treated with antibiotics in the last 90 days, two weeks post-partum or post-instrumentation.

Results: Of the 512 charts included in the analysis, 494 $(96.5 \%)$ patients had a urinalysis, of which $463(93.7 \%)$ had positive leukocyte esterase and $90(18.2 \%)$ had positive nitrites. 370 patients $(72.3 \%)$ had urine cultures performed, of which $236(63.8 \%)$ were positive. 505 (98.6\%) patients received antibiotics (53.9\% Macrobid; $22.6 \%$ Ciprofloxacin; $15.0 \%$ Septra; $6.7 \%$ other; $1.8 \%$ not documented). 7 (1.9\%) cultures grew organisms resistant to the prescribed antibiotic; $2(0.5 \%)$ patients received new prescriptions.

Conclusions: For the majority of young female patients with an uncomplicated UTI, urine cultures did not change management in the ED setting. However, when the diagnosis is uncertain based on symptomology and urinalyses alone, a urine culture may be warranted. Greater efforts should be directed towards educating emergency physicians on accurately diagnosing uncomplicated cystitis and the limited impact of urine cultures on treatment once a diagnosis has been made.

\section{RÉSUMÉ}

Objectifs: L'étude visait à déterminer le nombre de cultures d'urine demandées chez des femmes examinées au service des urgences (SU) pour des symptômes d'infection urinaire
(IU) sans complications, et à vérifier si les résultats des cultures influaient sur la prise en charge ultérieure.

Méthode: II s'agit d'un examen rétrospectif, d'une durée de un an, de dossiers médicaux de femmes non enceintes, âgées de 18 à 39 ans, qui sont allées à l'un des deux SU universitaires et chez qui un diagnostic de sortie d'IU sans complications a été posé. Les critères d'exclusion comprenaient un état fébrile documenté, l'immunovulnérabilité, le diabète sucré, l'absence de symptômes dans les voies urinaires basses, l'administration intraveineuse d'antibiotiques au SU, une IU antérieure traitée par les antibiotiques au cours des 90 jours précédents, un accouchement ou une intervention au cours des deux semaines précédentes.

Résultats: L'analyse a porté sur 512 dossiers. Un examen d'urine a été effectué chez 494 patientes (96,5\%); 463 (93,7\%) d'entre elles ont obtenu des résultats positifs à l'égard de l'estérase leucocytaire et 90 (18,2\%), à l'égard des nitrites. Par ailleurs, il y a eu 370 cultures d'urine (72,3\%), dont 236 $(63,8 \%)$ se sont révélées positives. Cinq cent cinq patientes $(98,6 \%)$ ont reçu des antibiotiques (Macrobid : 53,9 \%; ciprofloxacine : 22,6\%; Septra : 15,0\%; autres : 6,7\%; sans documentation : 1,8\%). Dans 7 cultures $(1,9 \%)$, les microorganismes étaient résistants à l'antibiotique prescrit, et 2 patientes $(0,5 \%)$ ont reçu une nouvelle prescription.

Conclusions: Dans la majorité des cas d'IU sans complications touchant de jeunes femmes, les cultures d'urine n'ont pas changé la prise en charge au SU. Toutefois, dans les cas où les symptômes et les résultats des examens d'urine seuls ne permettent pas de poser un diagnostic formel, il peut être justifié de demander une culture d'urine. Aussi devrait-on offrir davantage de formation aux urgentologues sur la justesse du diagnostic de cystite sans complications et sur la faible incidence des cultures d'urine sur le traitement une fois le diagnostic posé.

Keywords: urinary tract infection, antibiotics, emergency department, urine culture

From the *Department of Family \& Community Medicine, University of Toronto, Toronto, ON; †Schwartz/Reisman Emergency Medicine Institute, Toronto, ON; ¥Mount Sinai Hospital, Toronto, ON; and §North York General Hospital, Toronto, ON.

Correspondence to: Dr. Bjug Borgundvaag, Associate Professor, Department of Family \& Community Medicine, Mount Sinai Hospital, University of Toronto, 206-600 University Avenue, Toronto, ON M5G 1X5; Email: bjug.borgundvaag@ sinaihealthsystem.ca 


\section{INTRODUCTION}

Urinary tract infections (UTIs) are the most frequent bacterial infections in women and represent a large proportion of all ambulatory health care visits. ${ }^{1,2}$ In 2011, UTIs accounted for nearly 7 million office visits, a million visits to the emergency department (ED), and 100,000 hospitalizations in the United States. ${ }^{3}$ Nearly half of all women will have a UTI in their lifetime, with 1 in 3 females requiring antimicrobial therapy by the age of 24 years. $^{4}$

An acute uncomplicated UTI in the nonpregnant woman is considered a benign illness with no long-term medical sequelae. ${ }^{2,4}$ However, despite being commonly encountered in the ED, there is little consensus as to how to either diagnose or manage UTIs in healthy young women. ${ }^{5}$ Timely diagnosis of UTI can be made in the ED based on typical symptomatology (i.e., frequency, urgency, dysuria, hematuria) without vaginal discharge or irritation, and a urinalysis positive for the presence of leukocyte esterase and/or nitrites. ${ }^{6}$ However, there is concern that a diagnosis of UTI based on symptoms and a positive urinalysis may result in both high levels of unnecessary antimicrobial therapy and under-recognition of other infections and alternative diagnoses.

Current primary care guidelines do not specifically address the diagnosis of UTI but do recommend empiric treatment for patients with a suspected UTI without performing urine cultures. ${ }^{7}$ Empiric treatment is recommended for patients with at least two of the following: dysuria, presence of leukocytes (more than trace amounts), or presence of nitrites in the urine. Treatment is also recommended if the patient is uncomfortable, feels that the symptoms are severe, or does not want to wait for culture results. ${ }^{7}$ However, these recommendations may not be appropriate in the $\mathrm{ED}$, where patients may be more likely to perceive their condition as urgent. The guidelines also acknowledge that up to $40 \%$ of patients diagnosed with a UTI will have sterile urine. ${ }^{7,8}$ The challenge of diagnosing a UTI clinically has been confirmed in a recent systematic review, ${ }^{9}$ which concluded that individual symptoms and signs suggestive of a UTI have only a modest ability to confirm or exclude the diagnosis. While recommending that empiric treatment is cost-effective and simple for both the patient and provider, there is mounting evidence that prescribing antibiotics without confirmation of a bacterial infection is contributing to the development of growing antibiotic resistance among uropathogens. Additionally, failure to confirm the diagnosis of a UTI has also shown to result in underdiagnosis of other important causes of UTI symptoms, such as sexually transmitted infections. ${ }^{10,11}$

The primary objective of this study was to determine the number of urine cultures ordered for women presenting to the ED with symptoms of uncomplicated UTI. Secondary outcomes included the frequency of positive urine culture results, whether the culture result impacted initial antibiotic management, the urinalysis results, and the number of unplanned return ED visits within seven days.

\section{METHODS}

\section{Study design, setting and population}

This was a retrospective medical record review of women aged 18-39 years who presented to one of two EDs (annual censuses 60,000 and 100,000) of an academic tertiary-care hospital in Toronto, Ontario, with a discharge diagnosis of an uncomplicated UTI over a one-year study period (January to December of 2014). Charts were reviewed to make sure that women presented with at least one of the classical symptoms of UTI, such as frequency, urgency, dysuria, or hematuria. Patients were excluded if any of the following were documented: pregnancy, fever, immunocompromised state, diabetes mellitus, absence of lower urinary tract symptoms, ED administration of intravenous antibiotics, a previous UTI treated with antibiotics over the last 90 days, or less than 2 weeks postpartum or postinstrumentation. The study protocol was approved by the institutional research ethics board.

\section{Study protocol}

Using a computerized, structured data abstraction form, trained research personnel reviewed the medical records and extracted patient age, gender, Canadian Triage and Acuity Scale (CTAS) score, comorbidities, and ED length of stay. Research personnel also captured whether a urinalysis was performed, the results of the urinalysis, if a urine culture was ordered, and the results of the culture, along with the organisms and sensitivities. Whenever possible, the antibiotic prescribed by the attending emergency physician was recorded, along with any unplanned return ED visits 
within seven days and telephone calls made to patients in response to culture results. Periodic meetings with chart abstractors and study team investigators were held to resolve disputes and monitor performance. A second investigator performed a blinded critical review of a random sample of $15 \%$ of the medical records to determine inter-rater agreement.

\section{Outcomes}

The primary objective of this study was to determine the number of urine cultures ordered for women presenting to the ED with symptoms of uncomplicated UTI. Secondary outcomes included frequency of positive urine culture results, whether the culture result impacted initial antibiotic management, urinalysis results, and the number of unplanned return ED visits within seven days.

\section{Data analysis}

The data were entered directly into a study-specific Microsoft Excel database (Microsoft Corporation, Redmond, Washington). Descriptive statistics were summarized using means with standard deviations $(S D)$, medians with interquartile ranges $(I Q R)$, or frequencies with $95 \%$ confidence intervals where appropriate. Interrater agreement of medical record review was estimated using Cohen's kappa ( $\kappa$ ) statistic, with $\kappa<0.2$ interpreted as "poor agreement," $\kappa=0.2-0.4$ interpreted as "fair agreement," $\kappa=0.41-0.60$ interpreted as "moderate agreement," $\kappa=0.61-0.80$ interpreted as "good agreement," and $\kappa>0.80$ interpreted as "very good agreement." All statistical analyses were conducted using SAS (v. 9.3, SAS Institute, Cary, North Carolina).

\section{RESULTS}

A total of 512 medical records were included in the study (Table 1). Of these, 494 (96.5\%) patients had a urinalysis, of which 463 (93.7\%) had positive leukocyte esterase and 90 (18.2\%) had positive nitrites (Figure 1). Some 370 patients $(72.3 \%)$ had urine cultures performed, of which $236(63.8 \%)$ were positive.

Positive culture results ranged from 11 (47.8\%), 137 (64.6\%), and $81(63.3 \%)$ for CTAS 2, CTAS 3, and CTAS 4 patients, respectively (Table 2). Of the 463 $(93.7 \%)$ patients with positive leukocyte esterase on

\begin{tabular}{|c|c|c|c|}
\hline & $\begin{array}{l}\text { ED Site } 1 \\
(n=315)\end{array}$ & $\begin{array}{l}\text { ED Site } 2 \\
(n=197)\end{array}$ & $\begin{array}{c}\text { Total } \\
(N=512)\end{array}$ \\
\hline $\begin{array}{c}\text { Median (/QR) ED } \\
\text { LOS (hours) }\end{array}$ & $1.9(1.3,3.0)$ & $1.4(0.9,2.2)$ & $1.8(1.1,2.7)$ \\
\hline $\begin{array}{l}\text { Mean }(S D) \\
\text { patient age } \\
\text { (years) }\end{array}$ & $27.9(5.8)$ & $27.1(5.4)$ & $27.6(5.7)$ \\
\hline \multicolumn{4}{|l|}{ CTAS score } \\
\hline CTAS 2 & $31(9.8 \%)$ & $6(3.0 \%)$ & $37(7.2 \%)$ \\
\hline CTAS 3 & $191(60.6 \%)$ & $98(49.7 \%)$ & $289(56.4 \%)$ \\
\hline CTAS 4 & $93(29.5 \%)$ & 77 (39.1\%) & $170(33.2 \%)$ \\
\hline $\begin{array}{l}\text { Urinalysis } \\
\text { performed }\end{array}$ & 304 (96.5\%) & 190 (96.4\%) & $494(96.5 \%)$ \\
\hline $\begin{array}{l}\text { Positive } \\
\text { leukocytes }\end{array}$ & 285 (93.8\%) & 178 (93.7\%) & $463(93.7 \%)$ \\
\hline Positive nitrites & $50(16.4 \%)$ & $40(21.1 \%)$ & $90(18.2 \%)$ \\
\hline
\end{tabular}

CTAS = Canadian Triage and Acuity Scale; ED = emergency department; $I Q R=$ interquartile range; $L O S=$ length of stay; $S D=$ standard deviation.

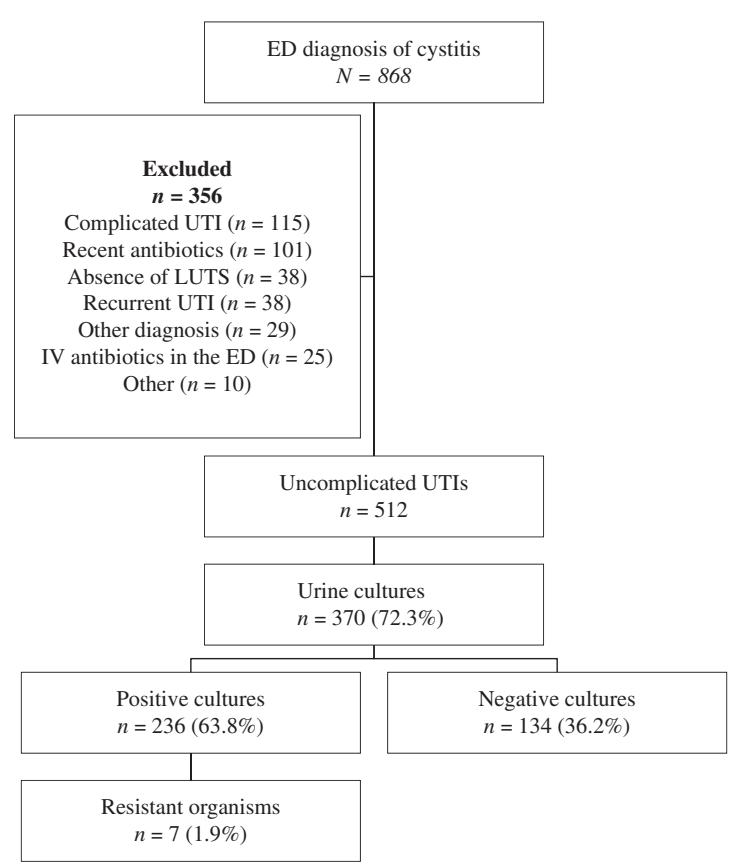

Figure 1. CONSORT diagram of included patients. $\mathrm{ED}=$ emergency department; $\mathrm{UTI}=$ urinary tract infection; LUTS = lower urinary tract symptoms; IV = intravenous.

urinalysis, 347 (74.9\%) had a urine culture sent, and 226 (65.1\%) came back positive. Of the 90 (18.2\%) patients with positive nitrites, $71(78.9 \%)$ had a urine culture sent, and 64 (90.1\%) came back positive. There were 89 (17.4\%) patients with both positive leukocyte esterase 


\begin{tabular}{|c|c|c|c|}
\hline & $\begin{array}{l}\text { Total } \\
(n, \%)\end{array}$ & $\begin{array}{l}\text { Culture } \\
\text { performed }\end{array}$ & $\begin{array}{l}\text { Positive } \\
\text { culture }\end{array}$ \\
\hline \multicolumn{4}{|l|}{ CTAS score } \\
\hline CTAS 2 & $37(7.2 \%)$ & $23(62.1 \%)$ & $11(47.8 \%)$ \\
\hline CTAS 3 & $289(56.4 \%)$ & $212(73.3 \%)$ & $137(64.6 \%)$ \\
\hline CTAS 4 & $170(33.2 \%)$ & $128(75.3 \%)$ & $81(63.3 \%)$ \\
\hline Urinalysis performed & $494(96.5 \%)$ & $367(74.3 \%)$ & $236(64.3 \%)$ \\
\hline Positive leukocytes & $463(93.7 \%)$ & $347(74.9 \%)$ & $226(65.1 \%)$ \\
\hline Positive nitrites & $90(18.2 \%)$ & $71(78.9 \%)$ & $64(90.1 \%)$ \\
\hline $\begin{array}{l}\text { Positive leukocytes } \\
\text { AND positive } \\
\text { nitrites }\end{array}$ & $89(17.4 \%)$ & $70(78.6 \%)$ & $64(91.4 \%)$ \\
\hline
\end{tabular}

\begin{tabular}{|c|c|c|c|}
\hline & $\begin{array}{l}\text { ED Site } 1 \\
(n=229)\end{array}$ & $\begin{array}{l}\text { ED Site } 2 \\
(n=141)\end{array}$ & $\begin{array}{c}\text { Total } \\
(N=370)\end{array}$ \\
\hline Positive urine cultures & $137(59.8 \%)$ & $99(70.2 \%)$ & $236(63.8 \%)$ \\
\hline E. coli & $104(75.9 \%)$ & $84(84.8 \%)$ & $188(79.7 \%)$ \\
\hline Klebsiella & $8(5.8 \%)$ & $3(3 \%)$ & $11(4.7 \%)$ \\
\hline ESBL (class A or C) & $8(5.8 \%)$ & 0 & $8(3.4 \%)$ \\
\hline Enterobacter & $4(2.9 \%)$ & $2(2 \%)$ & $6(2.5 \%)$ \\
\hline Other & $15(10.9 \%)$ & $11(11.1 \%)$ & $26(11.0 \%)$ \\
\hline
\end{tabular}

E. coli $=$ Escherichia coll; $\mathrm{ESBL}=$ extended-spectrum beta-lactamase-producing organisms.

and nitrites, $70(78.6 \%)$ had a urine culture sent, and 64 (91.4\%) came back positive.

Among patients who had a positive urine culture, the majority (79.7\%) grew Escherichia coli (Table 3). Other organisms included Klebsiella (4.7\%), extendedspectrum beta-lactamase-producing organisms (3.4\%), and Enterobacter (2.5\%). A total of 505 (98.6\%) patients received antibiotics (Table 4). Only slightly more than two-thirds $(347 / 505,68.7 \%)$ were treated with recommended first-line antibiotics (nitrofurantoin or trimethoprim/sulfamethoxazole) according to current primary care guidelines. ${ }^{7}$ Among the positive urine cultures, $7(1.9 \%)$ cultures grew organisms resistant to the prescribed antibiotic, of which 4 were resistant to first-line agents (nitrofurantoin). All 7 patients were notified of the culture results by telephone, and 2 $(0.5 \%)$ patients received new prescriptions. A total of 8 (1.6\%) patients had a planned return visit to the same ED within 7 days, all for a scheduled ultrasound with radiology. No patient had an unplanned return visit within 7 days to the same ED.

\begin{tabular}{|c|c|c|c|}
\hline & $\begin{array}{l}\text { ED Site } 1 \\
(n=315)\end{array}$ & $\begin{array}{l}\text { ED Site } 2 \\
(n=197)\end{array}$ & $\begin{array}{c}\text { Total } \\
(N=512)\end{array}$ \\
\hline $\begin{array}{l}\text { Patients who } \\
\text { received antibiotics }\end{array}$ & $310(98.4 \%)$ & $195(99.0 \%)$ & $505(98.6 \%)$ \\
\hline Nitrofurantoin & $155(50.0 \%)$ & $117(60.0 \%)$ & 272 (53.9\%) \\
\hline Ciprofloxacin & $78(25.2 \%)$ & $36(18.5 \%)$ & $114(22.6 \%)$ \\
\hline $\begin{array}{l}\text { Trimethoprim/ } \\
\text { sulfamethoxazole }\end{array}$ & $44(14.2 \%)$ & $31(15.9 \%)$ & $75(14.9 \%)$ \\
\hline Beta-lactam & $20(6.5 \%)$ & $9(4.6 \%)$ & $29(5.7 \%)$ \\
\hline $\begin{array}{l}\text { Other } \\
\text { fluoroquinolones }\end{array}$ & $3(1.0 \%)$ & $2(1.0 \%)$ & $5(1.0 \%)$ \\
\hline Not documented & $10(3.2 \%)$ & 0 & $10(1.9 \%)$ \\
\hline
\end{tabular}

\section{DISCUSSION}

The primary objective of this study was to determine the proportion of urine cultures sent for women presenting to the ED with symptoms of an uncomplicated UTI, and whether the culture result impacted subsequent management. Our results suggest that urine cultures and sensitivity testing are frequently ordered for ED patients who are treated for uncomplicated cystitis, and that the results of these tests rarely change the course of clinical care. These findings support current primary care management guidelines recommending that urine culture and sensitivity testing add little to clinical care and should not be performed unless the patient has complicating factors (pregnancy or less than two weeks postpartum, fever, immunocompromised state, diabetes mellitus, recent antibiotics, or recent instrumentation) or when the diagnosis is uncertain. ${ }^{7,12}$ Although nearly all patients in this study were treated with antibiotics, a large proportion had sterile urine, indicating other potentially important causes for their symptoms remaining undiagnosed. These results suggest that in the current era of multidrug-resistant microbes and antibiotic stewardship, the practice of simply treating patients empirically may no longer be justified, and the role of urine cultures needs to be clarified. ${ }^{13,14}$

Our findings are similar to previous reported studies. ${ }^{8,15}$ A small retrospective study by Phillips et al. ${ }^{15}$ reported 119/120 (99.2\%) patients with a discharge diagnosis of cystitis or UTI who had a urinalysis in the $\mathrm{ED}$, of which $112(94.1 \%)$ had positive leukocyte esterase and $22(18.5 \%)$ had positive nitrites. A total of $118(98.3 \%)$ of their patients received antibiotics. 
In our study, $96.5 \%$ patients had a urinalysis, of which 93.7\% had positive leukocyte esterase, $18.2 \%$ had positive nitrites, and $98.6 \%$ patients were treated with an antibiotic. Phillips et al. ${ }^{15}$ also reported that $72.3 \%$ of patients had urine cultures performed, of which $63.8 \%$ were positive, which is also very similar to our study findings. The results of our study support those of Philips et al. and suggest that routine use of urine cultures in young healthy women with an uncomplicated UTI is unnecessary and does not change management.

The frequency of positive urine culture results in our study is also similar to office-based primary care studies. McIsaac et al. ${ }^{8}$ described practice patterns for 246 family physicians managing patients with suspected cystitis and reported that physicians ordered a urine culture for $77.0 \%$ of the women with suspected UTI, and $67.2 \%$ were positive. At the office visit, an antibiotic was prescribed for $86.9 \%$ of the women. A prescription was more likely $(92.7 \%)$ if the urine dip was positive for either leukocytes or nitrites than if the dip was negative for both (70.1\%). Given that UTI is one of the most common reasons for antibiotic prescriptions in the ED, and that nearly all patients are empirically treated with antibiotics, we believe that there is a need for reexamination of the diagnosis and management of UTIs in the ED.

Similar to the evolution of the management of otitis media in children, one novel approach to patients with suspected UTI is to provide supportive/symptomatic care and only treat patients with antibiotics if they worsen or fail to improve within a few days. This approach has been explored in several recent primary care studies. ${ }^{16-18}$ In a blinded randomized controlled trial, Gágyor et al. ${ }^{16}$ compared a single dose of 3 grams of fosfomycin to ibuprofen $400 \mathrm{mg}$ three times daily for three days and found that symptoms resolved in two-thirds of patients in the ibuprofen group with no antibiotics at all. The authors concluded that initial symptomatic treatment is a possible approach to be discussed with women willing to avoid immediate antibiotics and accept a somewhat higher symptom burden. Several studies suggest that a significant proportion of women (in the primary care office setting) are willing, or may even prefer, to avoid antibiotics and are open to alternative treatment strategies. ${ }^{18,19}$ Larger studies should be undertaken in the ED setting to determine if this or other approaches targeted at reducing antibiotic use are acceptable to patients and providers and can reduce the use of antibiotics without adverse consequences.

\section{LIMITATIONS}

This study has several limitations. It was a small study, and the physician practice behaviour we observed was limited to two EDs. While clinical management strategies appeared similar across a large number of physicians at both institutions, our findings may not be generalizable to other settings. The nature of this retrospective medical record review carries inherent limitations. Though all patients included in the study had an ED diagnosis of UTI, and we excluded patients who were pregnant, febrile, immunocompromised, had diabetes mellitus, had an absence of lower urinary tract symptoms, had an ED administration of intravenous antibiotics, and had a previous UTI treated with antibiotics in the last 90 days, as well as patients who were two weeks postpartum or post-instrumentation, we cannot be sure that these were truly "uncomplicated" UTIs. Additionally, due to the retrospective nature of our study, we can only report what was documented on the patient charts. Patients may have been contacted regarding test results or treatment changes (including discontinuation of antibiotics), or they may have sought medical attention following their ED visit and received different advice from other health care providers or other self-treatment sources. We are unable to comment on antibiotic compliance, burden or duration of symptoms beyond the ED, the prevalence of adverse events, or subsequent clinical outcomes.

\section{CONCLUSIONS}

In this review of emergency physician management of healthy young women with suspected cystitis, we found that nearly all patients seen at two hospital EDs were prescribed antibiotics, and that $72.3 \%$ had urine cultures performed. These findings suggest that urine cultures and sensitivity testing are frequently ordered in the ED for patients who are treated for uncomplicated cystitis; however, the results of these tests rarely changed clinical care $(2 / 370 ; 0.5 \%)$ once the diagnosis had been made.

While this study supports current management guidelines recommending against the routine use of urine cultures for patients treated for an uncomplicated UTI, further study is required to develop clinical decision pathways directed at better identification of which ED patients would benefit from treatment in this era of increasing antimicrobial resistance. 
Acknowledgements: The work described in this manuscript has been formally presented at the following scientific meetings: the International Conference of Emergency Medicine, Cape Town, April 2016; the Society of Academic Emergency Medicine, New Orleans, May 2016; the Canadian Association of Emergency Physicians, Quebec City, June 2016; and the Family Medicine Forum, Vancouver, November 2016.

Competing interests: None to declare.

\section{REFERENCES}

1. Colgan R, Williams M. Diagnosis and treatment of acute uncomplicated cystitis. Am Fam Physician 2011;1;84(7): 771-6.

2. Little P, Merriman R, Turner S, et al. Presentation, pattern, and natural course of severe symptoms, and role of antibiotics and antibiotic resistance among patients presenting with suspected uncomplicated urinary tract infection in primary care: observational study. BMf 2010;340:b5633.

3. Salvatore S, Salvatore S, Cattoni E, et al. Urinary tract infections in women. Eur 7 Obstet Gynecol Reprod Biol 2011;156(2):131-6.

4. Foxman B. Epidemiology of urinary tract infections: incidence, morbidity, and economic costs. Am 7 Med 2002;113 (1A Suppl):5S-13S.

5. Saint S, Scholes D, Fihn SD, Farrell RG, Stamm WE. The effectiveness of a clinical practice guideline for the management of presumed uncomplicated urinary tract infection in women. Am $\mathcal{F}$ Med 1999;106(6):636-41.

6. Bent S, Nallamothu BK, Simel DL, Fihn SD, Saint S. Does this woman have an acute uncomplicated urinary tract infection? 7AMA 2002;287(20):2701-10.

7. Anti-Infective Review Panel. 2013. Anti-Infective Guidelines for Community-Acquired Infections. Toronto, ON: MUMS Guideline Clearinghouse.

8. McIsaac WJ, Prakash P, Ross S. The management of acute uncomplicated cystitis in adult women by family physicians in Canada. Can fै Infect Dis Med Microbiol 2008;19(4):287-93.

9. Giesen LG, Cousins G, Dimitrov BD, van de Laar FA, Fahey T. Predicting acute uncomplicated urinary tract infection in women: a systematic review of the diagnostic accuracy of symptoms and signs. BMC Fam Pract 2010; $11: 78$.

10. Shapiro T, Dalton M, Hammock J, et al. The prevalence of urinary tract infections and sexually transmitted disease in women with symptoms of a simple urinary tract infection stratified by low colony count criteria. Acad Emerg Med 2005;12(1):38-44.

11. Huppert JS, Biro F, Lan D, et al. Urinary symptoms in adolescent females: STI or UTI? $\mathcal{f}$ Adolesc Health 2007; 40(5):418-24.

12. Gupta K, Hooton TM, Naber KG, et al. International clinical practice guidelines for the treatment of acute uncomplicated cystitis and pyelonephritis in women: a 2010 update by the Infectious Diseases Society of America and the European Society for Microbiology and Infectious Diseases. Clin Infect Dis 2011;52(5):e103-20.

13. Hecker MT, Fox CJ, Son AH, et al. Effect of a stewardship intervention on adherence to uncomplicated cystitis and pyelonephritis guidelines in an emergency department setting. PLoS One 2014;9(2):e87899.

14. Hooton TM, Roberts PL, Cox ME, Stapleton AE. Voided midstream urine culture and acute cystitis in premenopausal women. $N$ Engl $f$ Med 2013;369(20): 1883-91.

15. Phillips DD, McLeod SL, Klingel M, et al. Do urine cultures in the emergency department change management of young women with symptoms of lower urinary tract infection? CFEM 2014;16(1 Suppl):S33.

16. Gágyor I, Bleidorn J, Kochen MM, et al. Ibuprofen versus fosfomycin for uncomplicated urinary tract infection in women: randomised controlled trial. BMF 2015;351: h6544.

17. Little P, Moore MV, Turner S, et al. Effectiveness of five different approaches in management of urinary tract infection: randomised controlled trial. BMF 2010;340:c199.

18. Knottnerus BJ, Geerlings SE, Moll van Charante EP, ter Riet G. Women with symptoms of uncomplicated urinary tract infection are often willing to delay antibiotic treatment: a prospective cohort study. BMC Fam Pract 2013;14:71.

19. Leydon GM, Turner S, Smith H, Little P, UTIS Team. Women's views about management and cause of urinary tract infection: qualitative interview study. BMF 2010; 340:c279. 